\title{
A method to obtain avian germ-line chimaeras using isolated primordial germ cells
}

\author{
Y. Yasuda ${ }^{1}$, A. Tajima ${ }^{2}$, T. Fujimoto ${ }^{1 *}$ and T. Kuwana ${ }^{1} \dagger$ \\ ${ }^{1}$ Department of Anatomy, Kumamoto University Medical School, Kumamoto, 860 Japan; and \\ ${ }^{2}$ Institute of Agriculture and Forestry, University of Tsukuba, Ibaraki, 305 Japan
}

\begin{abstract}
Summary. Primordial germ cells (PGCs), collected from the blood of 2-day-old chick embryos, were concentrated by Ficoll density centrifugation. The blood contained $0.048 \%$ PGCs and the concentrated fraction contained $3.9 \%$ PGCs in blood cells. The PGCs were picked up with a fine glass pipette, and one hundred were then injected into the terminal sinuses of 2-day-old Japanese quail embryos (24 somites); bubbles were then inserted to prevent haemorrhage. The embryos were further incubated at $38^{\circ} \mathrm{C}$ for $24 \mathrm{~h}$, and then fixed. Serial sections were stained with the periodic acid-Schiff reagent (PAS) to demonstrate chicken PGCs and with Feulgen stain to identify quail cells. On the basis of the differences in staining properties, 63.6 \pm 5.3 chick PGCs were detected in the quail embryo in the area where the gonads develop. Furthermore, $39 \cdot 3 \pm 4 \cdot 5$ chick PGCs were incorporated into the quail germinal epithelium within $24 \mathrm{~h}$ of the injection. A similar percentage of the host (quail) PGCs had also migrated to the germinal epithelium at the same stage of development. This technique for obtaining germ-line chimaeras will facilitate research on avian germ-line differentiation.
\end{abstract}

Keywords: primordial germ cells; migration; germ-line chimaera; chick; quail; transplantation

\section{Introduction}

The chicken-Japanese quail chimaeric gonad is a valuable model for studying the mechanism of germ-line establishment in Amniota (Tachinante, 1974; Hajji et al., 1988). This is because the avian embryo is more convenient to manipulate than that of mammals, and the detection of the donor cells among host cells in chicken-quail chimaeras is histologically possible with Feulgen staining (Le Douarin, 1973; Eyal-Giladi et al., 1981).

Primordial germ cells (PGCs) in birds originate in the epiblast (Eyal-Giladi et al., 1981) and first appear in the hypoblast of the area pellucida, i.e the germinal crescent, on the first day of incubation (Swift, 1914) at stage 4 (Hamburger \& Hamilton, 1951). PGCs appear in the blood circulation at stages 10-12 and concentrate in the area where gonads are developing, leave the blood (Ando \& Fujimoto, 1983; Ukeshima et al., 1991), and finally colonize the gonadal anlage (reviewed in Nieuwkoop \& Sutasurya, 1979). These features of PGC migration facilitate their isolation and transfer. Several methods for producing germ-line chimaeras have been described in birds, including the transplantation of germinal crescents (Tachinante, 1974; Hajji et al., 1988), injection of homogenized germinal crescent (Reynaud, 1969, 1976) or single cells from the crescent (Wentworth et al., 1989) into the circulation in 2-day-old embryos. The latest attempt published by Petitte et al. (1991) also transferred blood of 50-55 $\mathrm{h}$ incubated embryos into the recipient embryos incubated for 53, 72 and $96 \mathrm{~h}$. Some of these pioneering studies showed that the transferred PGCs

Present addressees: *Kawasaki College of Allied Health Professions, Kurashiki, Okayama, 701-01 Japan; †National Institute for Minamata Disease, Minamata, Kumamoto, 867 Japan. 
differentiate into germ cells that give rise to viable offspring (Reynaud, 1976; Wentworth et al., 1989).

We have now extended these studies, using the chicken-quail chimaeric gonad to quantify the pattern of settlement of donor chicken PGCs in the developing gonad of host quail embryos. Concurrently, we developed a method to obtain PGCs from blood, aiming to control the number of cells for injection or to impose any manipulation to the cells before injection. Chicken PGCs were found in the gonadal anlage of the host quail embryo $24 \mathrm{~h}$ after the counted chicken PGCs were transferred into the blood of 2-day-old quail embryos.

\section{Materials and Methods}

\section{Embryos}

Fertilized eggs of white Leghorn chicken (Gallus gallus domesticus) and Japanese quail (Coturnix coturnix japonica) were used in this experiment. The embryonic stage of development was defined according to Hamburger \& Hamilton (1951).

\section{Isolation of PGCs}

Blood was collected from a vitelline artery (omphalomesenteric artery), heart or terminal sinus of 2-day-old chick embryos (mainly stage 14 but including stage 13) with a fine glass pipette (usually, a disposable $50 \mu 1$ pipette, purchased from Drummond Scientific Co., Broomall, PA, used after drawing out using a tiny flame; the inner diameter of the drawn tip was about $50 \mu \mathrm{m}$ ). Blood, 1-5 $\mu$, was obtained from an embryo. Blood from 15-20 chick embryos was dispersed into the modified Hank's solution (cHBSS) at room temperature. Hank's balanced salt solution was supplemented with $1 \mathrm{mg}$ D-glucose $\mathrm{ml}^{-1}, 2 \mathrm{mmol} \mathrm{CaCl}{ }_{2} 1^{-1}$ and 1 mmol sodium phosphate $1^{-1}$. Hepes $\left(10 \mathrm{mmol}^{-1}\right)$ was added to keep the $\mathrm{pH}$ value at $7 \cdot 0$. These values are based on the physiological data for the early chick embryo given by Romanoff (1967). Fetal bovine serum was added at $10 \%(\mathrm{v} / \mathrm{v})$ to prevent PGCs from adhering to the substrate or aggregating with blood cells.

Ficoll (Pharmacia, Uppsala, Sweden) was dissolved at $10 \%(\mathrm{w} / \mathrm{v})$ in distilled water, dialysed against distilled water and then lyophilized to powder. It was then dissolved in cHBSS at $16 \%$ or $6.3 \%(\mathrm{w} / \mathrm{v})$. Pooled blood samples $(0.5 \mathrm{ml})$ were spun at $200 \mathrm{~g}$ for $2 \mathrm{~min}$. Pellets were then dispersed in $0.1 \mathrm{ml}$ cHBSS and mixed with $0.9 \mathrm{ml} 16 \%$ Ficoll in a microfuge tube $(1.5 \mathrm{ml}$ capacity), which was overlaid with $0.2 \mathrm{ml}$ of $6.3 \%$ Ficoll. After centrifugation at $800 \mathrm{~g}$ for $30 \mathrm{~min}$, the PGC-rich fraction located in the layer between $16 \%$ and $6.3 \%$ Ficoll was drawn up with a fine tip pipette ('yellow tip', Gilson Medical Electronics, Villiers-le-bel, France). The PGC-rich fraction was then diluted with cHBSS and spun at $200 \mathrm{~g}$ for $5 \mathrm{~min}$. The cells were suspended in a small volume of cHBSS (up to $0.1 \mathrm{ml}$ ) and finally placed in the centre of a dish (Falcon brand no. 1008, Becton Dickinson Co., Lincoln Park, NJ). Routinely 500-600 live PGCs were obtained from 20 chick embryos. The trypan blue exclusion method was used to evaluate viability of isolated PGCs. More than $99 \cdot 7 \%(n=8)$ of 100 PGCs which were picked up and pooled in a small droplet were viable.

\section{Transplantation of PGCs}

One hundred chick PGCs (cPGCs) were injected intravascularly into the blood area of the yolk sac in 2-day-old Japanese quail embryos (stage 15). PGCs were picked up from the PGC-rich fraction with a specially designed glass pipette (see below) under a phase contrast microscope. Before injection, a window (about $1.5 \mathrm{~cm}$ diameter) was opened at the sharp end of the quail egg shell after $1 \mathrm{ml}$ of egg white was removed from the blunt end with a 22 gauge needle and a $5 \mathrm{ml}$ syringe. The needle used for injection was a specially drawn Pyrex glass tube with an outer diameter of $900 \mu \mathrm{m}$ and with an inner diameter of $700 \mu \mathrm{m}$ and with an inner diameter at the tip of about $25 \mu \mathrm{m}$. The inner surface of the needle was coated, in advance, with a solution of silicon (Siliconize, Fuji Systems Inc., Tokyo, Japan) to avoid the loss of the PGCs from the inoculum by adhering to the inner wall of the needle. The volume of the inoculum was $1 \cdot 5-2 \cdot 0 \mu \mathrm{l}$ which was determined by measuring the diameter of droplets blown out from the needle. Injection was terminated by inserting cHBSS bubbles placed behind the inoculum within the needle, into the blood vessel. This prevented haemorrhages from the point of injection.

The window in the egg shell was sealed with Scotch brand no. 800 tape (3M, St Paul, MN, USA), and the operated quail embryo was further incubated at $38^{\circ} \mathrm{C}$ in a humidified chamber for $24 \mathrm{~h}$ to achieve maximum colonization and to minimize an increase in number owing to proliferation after injection (Meyer, 1964; Swartz \& Domm, 1972; see Discussion).

\section{Recording of the donor PGC distribution within the host embryo}

After incubation, the embryo was dissected and fixed with Rossman's fixative saturated picric acid in absolute ethanol and neutralized formalin $9: 1(\mathrm{v}: \mathrm{v})$ at $4^{\circ} \mathrm{C}$ for more than $4 \mathrm{~h}$, dehydrated in an ethanol series, and embedded in 
paraffin. Serial sections of $10 \mu \mathrm{m}$ were cut. Sections were prevented from detaching by coating slides with a thin layer of celloidin. The sections were then subjected to the periodic acid-Schiff technique (PAS) (Meyer, 1964) and covered with a coverslip using 50\% glycerol in phosphate-buffered saline (GIBCO brand no. 310-4040, GIBCO Labs, Grand Islands, NY) ( $\mathrm{pH} \mathrm{7.4).} \mathrm{The} \mathrm{location} \mathrm{and} \mathrm{number} \mathrm{of} \mathrm{cPGCs} \mathrm{in} \mathrm{the} \mathrm{quail} \mathrm{embryo} \mathrm{were} \mathrm{recorded} \mathrm{using} \mathrm{a} \mathrm{light} \mathrm{microscope}$ based on the fact that the cytoplasm of cPGCs stain a magenta colour with PAS (Meyer, 1961, 1964), whereas the cytoplasm of quail PGCs (qPGCs) do not stain (Swartz \& Domm, 1972). After the observation, the specimens were soaked in distilled water to remove the coverslip and nucleolus-associated heterochromatin of quail cells were stained with the Feulgen-Rossenbeck reaction (Le Douarin, 1973). The PAS-positive cells were re-examined to confirm that they were of chick origin (Le Douarin, 1973; Hajji et al., 1988).

The number of qPGCs in the gonadal region was recorded as described by Abercrombie (1946).

\section{Results}

PGCs in the blood collected from embryos were readily distinguished from blood cells, not only by their larger size $(14-19 \mu \mathrm{m})$ but also because of their appearance, when observed under the phase contrast microscope (Fig. 1a). The cells contained bright lipid droplets distributed in their cytoplasm and large asymmetrically located nuclei. In addition, the edges of PGCs appear as a bright ring beneath the cell membrane (see Fig. 1a-c), which is a good indication that the cells are alive (confirmed by trypan blue exclusion method, data not shown). Dying PGCs do not have this bright ring but appear translucent with dark granular cytoplasm (data not shown).

The number of PGCs in the circulating blood of stage 14 chick embryos (Fig. 1a) varies widely: the ratio of PGCs to blood cells was $0.00048 \pm 0.00009$ (mean \pm SEM). After Ficoll density centrifugation (Fig. 1b), there was no change in appearance and size of PGCs. The PGC:blood cell ratio increased to $0.039 \pm 0.0086$. PGCs could then be collected easily with a fine glass pipette (Fig. 1c). The total time required from blood collection to the recovery of the PGC-rich fraction was less than $2 \cdot 5 \mathrm{~h}$ for 20 eggs.

Eight quail embryos at stage 15 each received one hundred cPGCs; no embryo developed a haemorrhage at the injection site. They all grew to stage 20 after $24 \mathrm{~h}$ of incubation. Their morphological characteristics were not different from those of control quail embryos at stage 20 . The PAS-positive cPGCs (Fig. 2a, b) in the recipient quail embryos contained no Feulgen-positive heterochromatin except for a few tiny spots around the large Feulgen-negative nucleoli (Fig. 2c). The PAS-negative qPGCs (Fig. 2a, b), on the other hand, contained a few Feulgen-positive spots of heterochromatin around nucleoli and many small spots beneath the nuclear membrane (Fig. 2c).

No PAS-positive cPGCs in mitotic phase were found in the recipient quail embryo, although, on the basis of size and location, mitotic phase PGCs were found. However, pairs of PAS-positive cells of the same cell size and appearance were found in every embryo (mean $=2.88 \pm 0.35$ pairs). It is likely that they had undergone cell division.

Most PAS-positive PGCs (cPGCs) in the quail embryo were found in the coelomic mesoderm in the region caudal to the vitelline artery, medial to the mesonephros, dorsal to the hind-gut and ventral to the dorsal aorta, which was designated by Meyer (1964) as 'gonadal region', after $24 \mathrm{~h}$ of incubation (Fig. 2a). Chick PGCs located in the germinal epithelium, the thickened coelomic epithelium within the gonadal region, were scattered throughout the area. Many cPGCs found in the quail embryo displayed irregularly shaped contours (Fig. 2a, b), with some of the cells showing elongated cytoplasmic protrusions, as reported previously for the cells in normal chick embryos (Fujimoto et al., 1976). The number of cPGCs in various parts of the quail embryo other than the gonadal region was also recorded, and the data were combined into two categories: trunk and head (Table 1).

A mean of 76 cPGCs was observed in each quail embryo, and of these 63 were located in the gonadal region (Table 1). Within this region, $39 \mathrm{cPGCs}$ had migrated into the thickened germinal epithelium. The ratio of the distribution of host PGCs (qPGCs) between the epithelium and the mesenchyme (gonadal area) was 1.83 . This ratio for injected cPGCs was 1.63 and was not significantly different. 

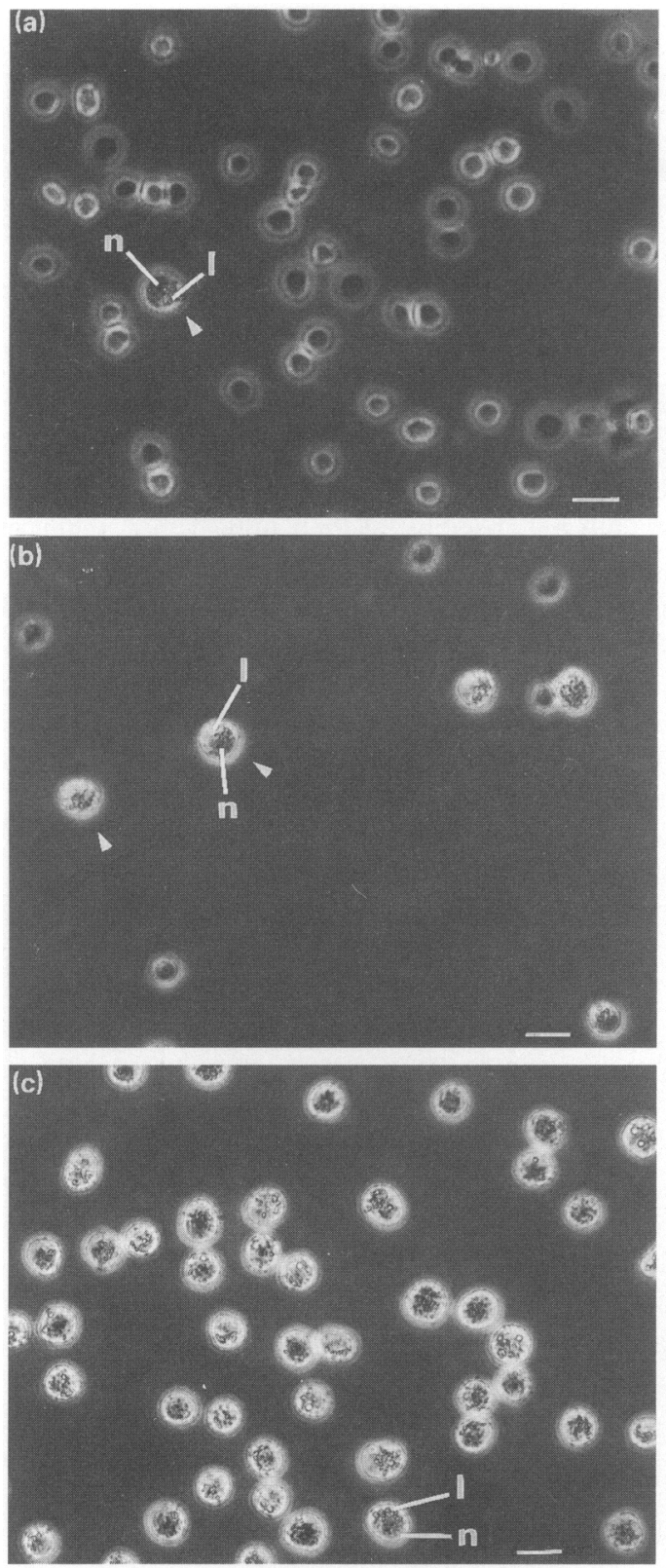

Fig. 1. (a) Primordial germ cells (PGCs) from the blood of stage 14 chick embryo were (b) concentrated as a primordial germ cell (PGC)-rich fraction by Ficoll density centrifugation. then (c) collected with a fine glass pipette. PGCs are indicated with arrowheads in (a) and (b). All the cells in (c) are PGCs. n: nucleus; l: lipid droplets can be seen as light spots. Bar shows $20 \mu \mathrm{m}$.

A mean of 14 ectopically located cPGCs was found in each host quail embryo. Half of these were in the head and the remainder were located between the mesonephros and coelomic epithelium, beside the neural tube in the middle of the trunk or in the neck, the basal region of the wing bud, the mandibular mesenchyme, the mesenchyme around the eye and around the 

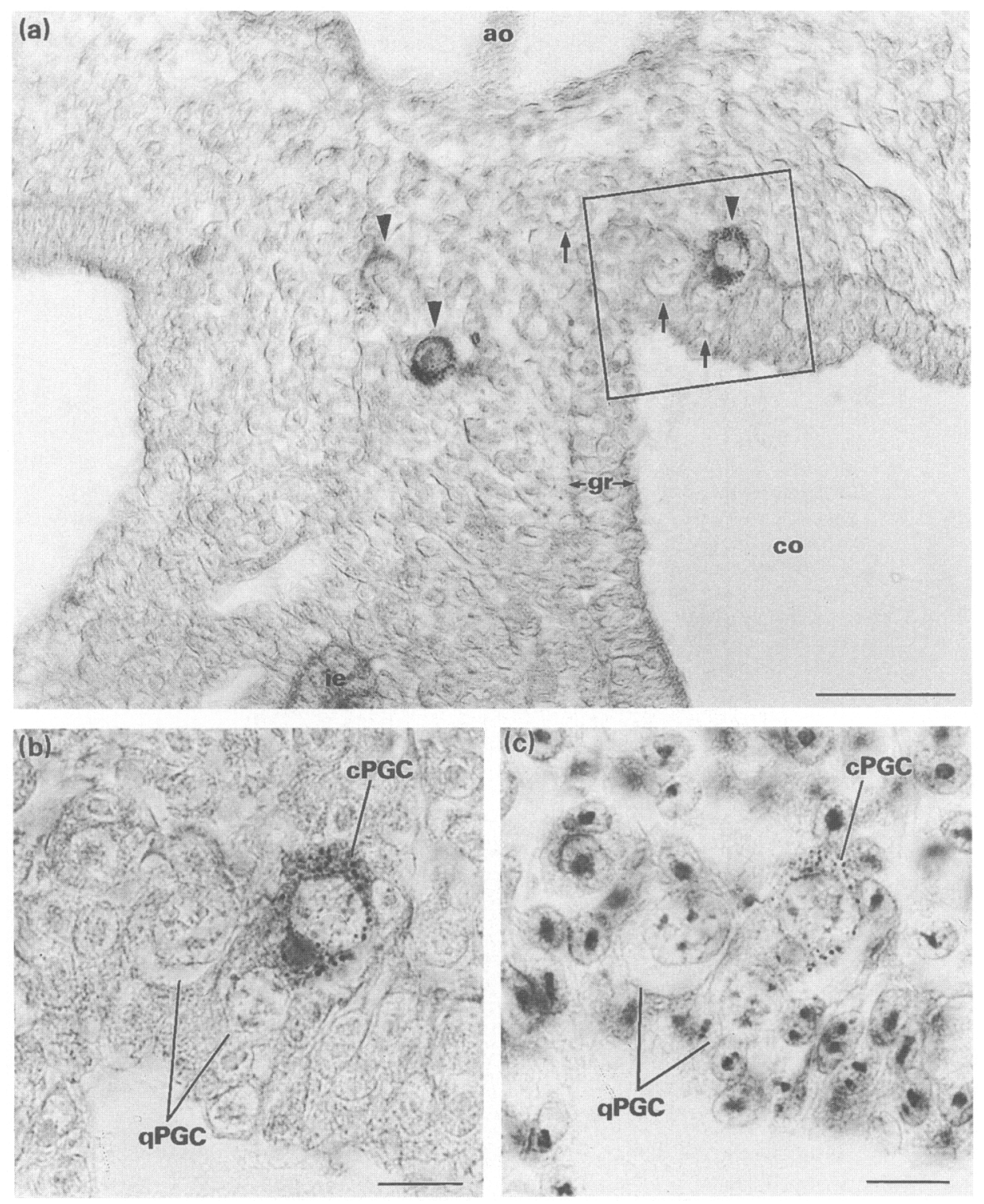

Fig. 2. (a) Chick primordial germ cells (cPGCs) (arrowheads) stained positive with periodic acid-Schiff reagents (PAS) can be seen in the quail gonadal region at $24 \mathrm{~h}$ of incubation after transfer of cPGCs. In this particular specimen, one cPGC can be seen in the left germinal epithelium (gr), and two in the mesentery. On the other hand, quail PGCs are PAS negative (arrows). co: Coelom; ie: intestinal endoderm (PAS positive); ao: dorsal aorta. Bar shows $40 \mu \mathrm{m}$. (b) A cPGC and two qPGCs in the square of Fig. 2(a) are shown with higher magnification. Bar shows $20 \mu \mathrm{m}$. (c) Feulgen staining facilitates the distinction between qPGC and cPGC by the stain of heterochromatin with Schiff's reagent, which is shown as dark spots in the nucleus of qPGC. Even though the size and number of Feulgen-positive heterochromatin are different from those of somatic quail cells (Hajji et al., 1988). Granules found in cytoplasm of cPGC are caused by PAS applied in advance (Fig. 2a, b). Both cPGC and qPGC are in the left germinal epithelium. Bar shows $10 \mu \mathrm{m}$. 
Table 1. The number of chick primordial germ cells (cPGCs) and quail primordial germ cells (qPGCs) in quail embryo $24 \mathrm{~h}$ after transplantation

\begin{tabular}{|c|c|c|c|c|c|}
\hline \multirow{2}{*}{$\begin{array}{l}\text { Sample } \\
\text { number }\end{array}$} & \multirow{2}{*}{$\begin{array}{l}\text { cPGC in } \\
\text { germinal } \\
\text { epithelium }\end{array}$} & \multirow{2}{*}{$\begin{array}{c}\text { cPGC in } \\
\text { gonadal } \\
\text { area }^{\mathbf{a}}\end{array}$} & \multicolumn{3}{|c|}{ cPGCs located in other tissues } \\
\hline & & & Trunk $^{\mathrm{b}}$ & Head & Total \\
\hline 1 & 55 & 22 & 2 & 5 & 84 \\
\hline 2 & 42 & 11 & 5 & 7 & 65 \\
\hline 3 & 54 & 26 & 10 & 0 & 90 \\
\hline 4 & 25 & 20 & 8 & 6 & 59 \\
\hline 5 & 23 & 34 & 11 & 13 & 81 \\
\hline 6 & 30 & 36 & 12 & 9 & 87 \\
\hline 7 & 49 & 34 & 4 & 0 & 82 \\
\hline 8 & 36 & 12 & 2 & 13 & 63 \\
\hline $\begin{array}{l}\text { Mean } \pm \text { SEM } \\
\text { qPCGs }^{c} \pm \text { SEM }\end{array}$ & $\begin{array}{c}39 \pm 4 \cdot 5 \\
365 \pm 41\end{array}$ & $\begin{array}{r}24 \pm 3 \cdot 5 \\
199 \pm 29\end{array}$ & $7 \pm 1 \cdot 4$ & $7 \pm 1.8$ & $\begin{array}{r}76 \pm 4 \cdot 3 \\
564 \pm 61\end{array}$ \\
\hline
\end{tabular}

${ }^{a}$ Gonadal area is the region including the dorsal mesentery and dorsal part of the coelomic wall and limited as follows: region caudal to vitelline artery, medial to mesonephros, dorsal to hind-gut and ventral to dorsal aorta. Caudal end of gonadal area was set at caudal terminus of coelom. Coelomic epithelium in this region was designated as germinal epithelium and was omitted in this column.

${ }^{\text {b }}$ Trunk includes whole embryo except gonadal region and head (region rostral to mandibular arch).

${ }^{c}$ Number of host quail PGCs. Mean of eight samples.

developing brain. Most of the cPGCs in the cephalic region remained within blood vessels (data not shown).

\section{Discussion}

It had been reported that PGCs derived from transplanted germinal crescent reach the host gonad and differentiate to germ cells there (Reynaud, 1976; Hajji et al., 1988). Transplantation of germinal crescent is effective in producing germ-line chimaeras but is difficult to perform. It seems much easier to inject blood containing PGCs into (Wentworth et al., 1989) or close to (Petitte et al., 1991) host blood vessels. In all these published procedures, it is difficult to control the number of PGCs in the inoculum and consequently the efficiency of transplantation. Furthermore, the present procedure makes it easier to manipulate PGCs before injection, for various experimental purposes.

Owing to the wide variations in the concentration of both PGCs and blood cells in 2-day-old embryos, PGCs from blood could not be concentrated as efficiently using Ficoll or Percoll (Pharmacia Inc., Sweden) density centrifugation, as can PGCs from mice (De Felici \& McLaren, 1983). Nevertheless, after concentration on a Ficoll gradient, the ratio of PGCs to blood cells increased more than 80 times and reached the concentration at which they could easily be collected by picking them up with a glass needle. In addition, the fact that 500-600 PGCs can be collected within $2.5 \mathrm{~h}$ may lead to various applications. For example, culture conditions of PGCs could be developed for studies on the properties of germ lines, or the role of extracellular matrix could be studied using cells in the migratory phase offering an alternative to neural crest cells. Moreover, the PGC injection method used in this study could enable the PGCs to play a role as a novel vehicle for gene transfection studies.

The process of PGC migration from the vascular system to the germinal epithelium in avian species can be divided into at least two steps: (i) concentration in the medial part of coelomic mesenchyme caudal to vitelline (omphalomesenteric) artery, i.e. gonadal region, and (ii) incorporation into the germinal epithelium (see below) after leaving the vascular system. The first step 
could be explained on the basis of the way in which architecture of the peripheral vascular system develops, since injected particles the size of PGCs were exclusively located in the fine capillary networks in the gonadal region and within the head at stage 16 (T. Kuwana, Y. Kajiwara and Y. Yasuda, unpublished). To achieve the second step, PGCs must respond to some trophic influence to enable them to leave the bloodstream and enter the germinal epithelium (Simon, 1960; Dubois et al., 1976; Godin et al., 1990). This is suggested by the observation that the PGCs reached the capillary network in the gonadal region rather than that in the head (Meyer, 1964). In this study chick PGCs inoculated into the quail embryo also reached the gonadal region rather than the head or other areas. Table 1 indicates that a mean of $63.6 \mathrm{cPGCs}$ per embryo reached step (i) and 39 step (ii) within $24 \mathrm{~h}$ after the injection, as in normal development. It remains to be determined whether the mean $24 \mathrm{cPGCs}$ present in the mesenchyme in the gonadal region (Table 1) are incorporated into the germinal epithelium in the following $24 \mathrm{~h}$, or are incorporated into the developing gonad without reaching the epithelium. Most of the PGCs leave the vascular channel within the coelomic mesenchyme of the gonadal region at stages 16-17 (day 2.5) and are likely to migrate into the thickened germinal epithelium in the coelomic angle (Meyer, 1964) within the next $24 \mathrm{~h}$ (reviewed in Nieuwkoop \& Sutasurya, 1979). This mode of incorporation of PGCs into the germinal epithelium is suggested by the following observations. First, most PGCs in the embryo at the time when they escape from the vessels in the coelomic mesenchyme are observed in the gonadal region (Ando \& Fujimoto, 1983). Second, PGCs in the coelomic mesenchyme display active movement (Fujimoto et al., 1976). Third, almost all of the PGCs in the gonadal region can be seen within the developing gonad 1.5 days after extravasation has been completed (Meyer, 1964; Fujimoto et al., 1976). However, it remains to be determined whether the incorporation of PGCs into the gonadal epithelium at such an early stage is critical for subsequent development as germ cells.

Swartz \& Domm (1972) observed that the number of dividing PGCs in the chick embryo increases steeply from $48 \mathrm{~h}$ to $72 \mathrm{~h}$ of incubation. In the present study, no PAS-positive mitotic phase cell was found. The number of cPGCs injected into a quail embryo was probably too small for any to be observed undergoing mitosis. Alternatively, during the mitotic phase cPGCs may lack PAS-positive activity in the cytoplasm. According to Swartz \& Domm (1972), 2\% of PGCs can be seen dividing in the intact 3-day-old embryo. After taking into account the large variation in the number of PGCs within embryos observed by those authors as well as the fact that colchicine was not used in the present study to facilitate the identification of dividing cells, it cannot be assumed that the injected cPGCs did not undergo mitosis. It is likely that the number of injected cPGCs found in the quail embryos increased during incubation. The periods of the cell cycles of intact or injected cPGCs are unknown, but if it is $24 \mathrm{~h}$, and if PGCs suffer no retardation in cell cycle during operation, then all cPGCs found in quail embryos went through division at least once. If this is so, the real number of $\mathrm{cPGCs}$ showed in Table 1 could represent at most twice the number in the quail embryo.

A mean of $24 \mathrm{cPGCs}$ injected into the quail embryo could not be traced (Table 1). The loss of the cPGCs cannot be attributed to leakage from the point of injection, since care was taken to avoid haemorrhage. Some PGCs were observed in the extraembryonic area of the host (mean $0.63 \pm 0.26$ ), but cannot fully account for the loss. It is possible that cPGCs were lost because of occasional death and absorption within the host embryo.

We are grateful to J. Bartman (Tropical Agricultural Research Institute, Tsukuba 305, Japan) for commenting on the manuscipt. Y. Yasuda, A. Tajima and T. Fujimoto were recipients of a grant in aid from the Ministry of Education Science and Culture, Japan.

\section{References}

Abercrombie, M. (1946) Estimation of nuclear population from microtome sections. Anatomical Record 94, 239-247.
Ando, Y. \& Fujimoto, T. (1983) Ultrastructural evidence that chick primordial germ cells leave the bloodvascular system prior to migration to the gonadal 
anlagen. Development Growth and Differentiation 25, 345-352.

Dubois, R., Cuminge, D. \& Smith, J. (1976) Interpretation of some recent results in experimental embryology and the problem of the germ line. In Organic Culture in Biological Research, pp. 61-93. Ed B.M. Monnickendam. Cambridge University Press, London.

De Felici, M. \& McLaren, A. (1983) In vitro culture of mouse primordial germ cells. Experimental Cell Research 144, 417-427.

Eyal-Giladi, H., Ginsburg, M. \& Fabarov, A.A. (1981) Avian primordial germ cells are of epiblastic origin. Journal of Embryology and Experimental Morphology $65,139-147$.

Fujimoto, T., Ukeshima, A. \& Kiyofuji, R. (1976) The origin, migration and morphology of the primordial germ cells in the chick embryo. Anatomical Record $185,139-154$.

Godin, I., Wylie, C. \& Heasman, J. (1990) Genital ridges exert long-range effects on mouse primordial germ cell numbers and direction of migration in culture. Development 108, 357-363.

Hajii, K., Martin, C. Perramon, A. \& Dieterlen-Lievre, F. (1988) Sexual phenotype of avian chimeric gonads with germinal and stromal cells of opposite genetic sexes. Biological Structures and Morphologenesis 1, 107-116.

Hamburger, V. \& Hamilton, H. L. (1951) A series of normal stages in the development of the chick embryo. Journal of Morphology 88, 49-92.

Le Douarin, N.M. (1973) A biological cell labelling technique and its use in experimental embryology. Developmental Biology 30, 217-222.

Meyer, D.B. (1961) The intra-embryonic migration of primordial germ cells in staged chick embryos. Anatomical Record 139, 314-315.

Meyer, D.B. (1964) The migration of primordial germ cells in the chick embryo. Developmental Biology 10, $154-190$.

Nieuwkoop, P.D. \& Sutasurya, L.A. (1979) The migration of the primordial germ cells. In Primordial Germ Cells in the Chordates, pp. 113-127. Cambridge University Press, London.
Petitte, J.N., Clark, M.E. \& Etches, R.J. (1991) Assessment of functional gametes in chickens after transfer of primordial germ cells. Journal of Reproduction and Fertility 92, 225-229.

Reynaud, G. (1969) Transfer de cellules germinales primordiales de Dindon à l'embryon de Poulet par injection intravasculaire. Journal of Embryology and Experimental Morphology 21, 485-507.

Reynaud, G. (1976) Capacités reproductrices et descendance de Poulets ayant subi un transfert de cellules germinales primordiales durant la vie embryonnaire. Wilhelm Roux's Archives for Developmental Biology 179, 85-110.

Romanoff, A.L. (1967) Biochemistry of the avian embryo: a Quantitative Analysis of Prenatal Development. John Wiley \& Sons, New York.

Simon, D. (1960) Contribution à l'étude de la circulation et du transport des gonocytes primaires dans les blastodermes d'oiseaux cultivés in vitro. Archives d'Anatomie Microscopique et de Morphologie Expérimentale 49, 93-176.

Swartz, W.J. \& Domm, L.V. (1972) A study on division of primordial germ cells in the early chick embryo. American Journal of Anatomy 135, 51-70.

Swift, C.H. (1914) Origin and early history of the primordial germ-cells in the chick. American Journal of Anatomy 15, 483-516.

Tachinante, F. (1974) Sur les échanges interspécifiques de cellules germinales entre le poulet et la caille, en culture organotypique et en greffes coelomiques. Comptes Rendus de l'Academie des Sciences, Paris 278, 1895-1898.

Ukeshima, A., Yoshinaga, K. \& Fujimoto, T. (1991) Scanning and transmission electron microscopic observations of chick primordial germ cells with special reference to the extravasation in their migration course. Journal of Electron Microscopy, 40, $124-128$.

Wentworth, B.C., Tsai, H., Hallett, J.H., Gonzales, D.S. \& Rajcic-Spasojevic, G. (1989) Manipulation of avian primordial germ cells and gonadal differentiation. Poultry Science 68, 999-1010.

Received 15 August 1991 